\title{
Sirtuin1 expression predicts the efficacy of neoadjuvant chemotherapy for locally advanced uterine cervical cancer
}

\author{
MASATOMO TERAMAE, TAKESHI FUKUDA, TAKUMA WADA, MASARU KAWANISHI, \\ KENJI IMAI, MAKOTO YAMAUCHI, TOMOYO YASUI and TOSHIYUKI SUMI
}

\author{
Department of Obstetrics and Gynecology, Osaka City University Graduate School of Medicine, \\ Abeno-ku, Osaka 545-8585, Japan
}

Received July 16, 2014; Accepted September 21, 2014

DOI: $10.3892 / \mathrm{mco} .2014 .427$

\begin{abstract}
Cisplatin-based, cyclic balloon-occluded arterial infusion, neoadjuvant chemotherapy (NAC) has previously been reported to enable hysterectomy in patients with locally advanced cervical cancer. Sirtuin1 (SIRT1) is a nicotinamide adenine dinucleotide $\left(\mathrm{NAD}^{+}\right)$-dependent histone deacetylase that deacetylates a number of proteins and is overexpressed in several human malignancies. Upregulation of SIRT1 has been reported to induce tumorigenesis and chemoresistance. To assess the role of SIRT1 in uterine cervical cancer, the outcomes in 62 patients aged $<70$ years with locally advanced International Federation of Gynecology and Obstetrics (FIGO) stage IIIA-IIIB uterine cervical cancer were reviewed between 1995 and 2010. Tumor samples were obtained by biopsy prior to NAC. The patients were separated into two groups. One group comprised of the patients in which NAC was effective, surgery and radiotherapy were performed (NAC+OP+R group; $\mathrm{n}=35$ ), and the second group contained patients in which NAC was ineffective and radiation therapy was performed (NAC+R group; $n=27)$. SIRT1 and p53 expression was assessed immunohistochemically in paraffin-embedded sections. SIRT1 expression was significantly higher in the NAC+R compared to the $\mathrm{NAC}+\mathrm{OP}+\mathrm{R}$ group $(\mathrm{P}<0.001)$, as was $\mathrm{p} 53$ expression $(\mathrm{P}=0.001)$. The overall survival time was significantly longer in the $\mathrm{NAC}+\mathrm{OP}+\mathrm{R}$ compared to the $\mathrm{NAC}+\mathrm{R}$ group $(\mathrm{P}=0.001)$. Following the division of patients into two groups based on SIRT1 level, low (weighted score $\leq 4, n=30$ ), and high level (weighted score $\geq 6, n=32$ ) groups, the former group was significantly more sensitive to NAC $(\mathrm{P}<0.001)$. Collectively, these results indicate that SIRT1 expression may predict the efficacy of NAC as a treatment for locally advanced uterine cervical cancer.
\end{abstract}

Correspondence to: Dr Takeshi Fukuda, Department of Obstetrics and Gynecology, Osaka City University Graduate School of Medicine, 1-4-3 Asahimachi, Abeno-ku, Osaka 545-8585, Japan E-mail: takeshif@med.osaka-cu.ac.jp

Key words: sirtuin1, neoadjuvant chemotherapy, uterine cervical cancer

\section{Introduction}

Sirtuin1 (SIRT1), one of the seven members (SIRT1-7) of the silent information regulator 2 (Sir2) family in mammals, has activity as a nicotinamide adenine dinucleotide $\left(\mathrm{NAD}^{+}\right)$-dependent histone deacetylase (HDAC) (1-3). SIRT1 deacetylates several key proteins that regulate the cell cycle and apoptosis, including Foxo family proteins, Ku70 and p53, and plays important roles in cell survival (4-7).

SIRT1 was previously reported to be upregulated in several tumor cell lines and human tumors (8-11). Upregulation of SIRT1 may induce tumorigenesis and resistance to certain chemotherapeutic agents (12). When normal cells undergo stress, such as DNA damage, p53 is activated, which results in the transcription of the hypermethylated in cancer 1 ( $\mathrm{HICl})$ gene (13). HICl represses transcription of the gene encoding $S I R T 1$, inducing pathways leading to cell senescence or apoptosis. However, during the early stage of tumor progression, epigenetic silencing of $\mathrm{HICl}$ leads to upregulation of SIRTI. Upregulated $S I R T 1$ inactivates $\mathrm{p} 53$ by deacetylation, impairing the functions of p53 and leading to a defective apoptotic response to DNA damage. This allows cells to reproduce in the presence of damaged DNA, resulting in the accumulation of mutations, including p53. Upregulated mutant p53 interferes with the functions of wild-type p53, disrupting cell-cycle control and promoting tumor progression $(14,15)$.

Locally advanced uterine cervical cancer is extremely difficult to treat. The standard treatment for patients with International Federation of Gynecology and Obstetrics (FIGO) stage IIIA, IIIB, and IVA uterine cervical cancer consists of concurrent chemoradiotherapy (CCRT) $(16,17)$, but patient prognosis is poor $(18,19)$. Successful neoadjuvant chemotherapy (NAC), followed by hysterectomy, has been reported to be effective in patients with locally advanced, uterine cervical cancer (20), with a prognosis equal to that of CCRT. However, the prognosis is worse if NAC is unsuccessful, as hysterectomy cannot be performed, and consequently, the treatment strategy must be changed from surgery to radiation therapy, resulting in a crucial delay $(21,22)$. Thus, it is important to identify prognostic factors in patients with locally advanced cervical cancer that predict whether NAC is likely to be successful (23-27).

Thus far, the expression of SIRT1 has not been assessed in patients with locally advanced uterine cervical cancer. 
Therefore, the present study was designed to examine the correlation between SIRT1 expression and the efficacy of NAC for locally advanced, uterine cervical cancer.

\section{Patients and methods}

Patients and samples. The retrospective study included 62 patients aged $<70$ years with locally advanced uterine cervical cancer (FIGO stages IIIA and IIIB), initially treated at the Osaka City University Medical School Hospital (Osaka, Japan) between 1995 and 2010. Tumor samples were obtained by biopsy prior to NAC. The patients were divided into two groups: One in which NAC was effective, surgery was possible and radiation therapy was performed $(\mathrm{NAC}+\mathrm{OP}+\mathrm{R}$ group; $\mathrm{n}=35$ ), and the second in which NAC was ineffective and, therefore, radiation therapy alone was performed (NAC+R group; $\mathrm{n}=27$ ). Additionally, patients were further divided into groups that attained complete/partial remission (CR+PR) and stable/progressive disease (SD+PD) in response to NAC. Written informed consent was obtained from all the patients prior to immunohistochemical examination. The study was approved by the Ethics Committee of Osaka City University (IRB no. 2581).

Balloon-occluded arterial infusion chemotherapy (BOAI) for $N A C$. Pelvic angiography was performed under local anesthesia using Seldinger's technique (28) to localize the tumor and feeder vessels. A balloon-wedge single-pressure catheter $(5 \mathrm{~F}, 80 \mathrm{~cm}$ in length; Dispomedica GmbH, Hamburg, Germany) was inserted into each femoral artery and subsequently into the internal iliac artery. The balloon catheters were advanced until they reached the vicinity of the feeder vessel (usually the uterine artery), where the balloon was inflated to interrupt local blood flow. cis-Diamminedichloroplatinum (CDDP) was slowly infused intra-arterially through the two catheters over a period of $30 \mathrm{~min}$ (28). The two ovarian arteries were blocked following the first round of BOAI to increase the intratumor concentration of CDDP. BOAI was performed three times in each patient to shrink the tumor. Adequate hydration was ensured prior to and following CDDP administration, and anti-emetics and diuretics were administered as appropriate. CDDP was administered at doses of 50,75 , or $100 \mathrm{mg} / \mathrm{m}^{2}$, depending on patient age and renal function. The efficacy of CDDP arterial infusion therapy was evaluated by cytology, histology, serum tumor marker level and magnetic resonance imaging (MRI) prior to the initiation of CDDP treatment. The results were compared with those obtained following the completion of each arterial infusion. MRI was used to estimate tumor regression by measuring its size in two dimensions $(29,30)$. Tumor tissue was obtained from all the patients who had undergone punch biopsy or surgery.

Immunohistochemical analysis. The expression of SIRT1 and p53 was examined in paraffin-embedded sections using antibodies to SIRT1 and p53, respectively, and the avidin-biotin peroxidase complex method. Briefly, $4-\mu$ m paraffin sections were deparaffinized and immersed in $3 \%$ hydrogen peroxidase in methanol to block endogenous peroxidase activity. The antigen was retrieved by immersing the slides in $10 \mathrm{mM}$ citrate buffer (pH 6.0) and heating in an autoclave at $110^{\circ} \mathrm{C}$ for $20 \mathrm{~min}$, followed by washing in phosphate-buffered solutions (PBS). The manufacturers' instructions were followed for the Dako
LSAB 2 peroxidase kit (Dako, Kyoto, Japan). The sections were incubated with a 1:100 dilution of polyclonal rabbit anti-human SIRT1 (Santa Cruz Biotechnology, Inc., Santa Cruz, CA, USA) or a 1:100 dilution of monoclonal mouse anti-human p53 (Santa Cruz Biotechnology, Inc.) overnight at $4^{\circ} \mathrm{C}$. The sections were washed with PBS for 15 min and incubated for 10 min with biotinylated goat anti-mouse or anti-rabbit immunoglobulin G (Dako). The sections were incubated with the streptavidin-peroxidase complex, with 3,3'-diaminobenzidine used as the chromogen. Finally, the sections were counterstained with Mayer's hematoxylin. The specificity of the immunohistochemical reactions was checked by omitting the primary antibody. SIRT1 and p53 expression was quantitatively analyzed as described (31). The mean percentage of positive tumor cells was determined in five separate areas (magnification, $x 400$ ), with positivity rates of $<5,5-25,25-50,50-75$ and $>75 \%$ scored as $0-4$, respectively. The staining intensity was scored as weak (1+), moderate (2+), or intense (3+). For each specimen, the percentage of positive tumor cells was multiplied by the staining intensity to yield a weighted score.

Statistical analysis. Data are presented as mean \pm standard deviation. The Kaplan-Meier and log-rank tests were performed for prognostic analysis. Weighted scores were compared using the Mann-Whitney U test. Student's t-test and the $\chi^{2}$ test were performed as appropriate for between-group comparisons. SPSS software, version 21.0 (IBM, Armonk, NY, USA), was used for all the statistical analyses. $\mathrm{P}<0.05$ was considered to indicate a statistically significant difference.

\section{Results}

Patient characteristics. In total, 35 of the 62 patients with locally advanced, uterine cervical cancer were assigned to the NAC+OP+R group and 27 to the NAC+R group. The mean ages were 49.3 (range, 24-69 years) and 52.3 years (range, 36-68 years), respectively. Of the 35 patients in the $\mathrm{NAC}+\mathrm{OP}+\mathrm{R}$ group, one was classified as stage IIIA and 34 as stage IIIB, whereas all the 27 patients in the NAC+R group were classified as stage IIIB. Histologically, 30 patients in the $\mathrm{NAC}+\mathrm{OP}+\mathrm{R}$ group were classified as having squamous cell carcinoma and five as having adenocarcinoma. A total of 22 patients in the NAC+R group were classified as having squamous cell carcinoma, three as having adenocarcinoma, and one each as having adenosquamous carcinoma and glassy cell carcinoma. There were no significant differences between the two groups (Table I).

Expression of SIRTI. SIRT1 was expressed in the nuclei of the tumor cells (Fig. 1). The weighted scores in the two groups are shown in Table II. The mean weighted score for SIRT1 expression was significantly lower in the $\mathrm{NAC}+\mathrm{OP}+\mathrm{R}$ compared to the NAC+R group ( 3.97 vs. 8.67, P<0.001; Fig. 2). In total, 30 of the 62 patients had weighted scores of 0-4 (low expression) and 32 had weighted scores of 6-12 (high expression). There were no significant differences between these two groups (Table III).

Expression of p53.p53 was expressed in the nuclei of the tumor cells. The weighted scores are shown in Table IV. The mean weighted score for p53 expression was also significantly lower 
Table I. Characteristics of patients in the $\mathrm{NAC}+\mathrm{OP}+\mathrm{R}$ and NAC + R groups.

\begin{tabular}{lccc}
\hline & NAC+OP+R & NAC+R & P-value \\
\hline Patients, n & 35 & 27 & \\
Age, years & & & \\
Mean \pm SD & $49.3 \pm 12.7$ & $52.3 \pm 11.1$ & $0.322^{\mathrm{a}}$ \\
Range & $24-69$ & $36-68$ & \\
FIGO stage, $\mathrm{n}$ & & & \\
IIIA & 1 & 0 & $0.376^{\mathrm{b}}$ \\
IIIB & 34 & 27 & \\
Histology, n & & & \\
SCC & 30 & 22 & $0.433^{\mathrm{b}}$ \\
A & 5 & 3 & \\
AS & 0 & 1 & \\
Others & 0 & 1 & \\
\hline
\end{tabular}

${ }^{\text {aS }}$ Student's t-test; ${ }^{\mathrm{b}} \chi^{2}$ test; $\mathrm{NAC}+\mathrm{OP}+\mathrm{R}$, neoadjuvant chemotherapy + surgery + radiotherapy; NAC+R, neoadjuvant chemotherapy + radiotherapy; FIGO, International Federation of Gynecology and Obstetrics; SCC, squamous cell carcinoma; A, adenocarcinoma; AS, adenosquamous carcinoma; SD, standard deviation.

Table II. Weighted scores of SIRT1 expression in the $\mathrm{NAC}+\mathrm{OP}+\mathrm{R}$ and $\mathrm{NAC}+\mathrm{R}$ groups .

\begin{tabular}{lcc}
\hline & \multicolumn{2}{c}{ Patients, $\mathrm{n}$} \\
\cline { 2 - 3 } Weighted score & $\mathrm{NAC}+\mathrm{OP}+\mathrm{R}$ & $\mathrm{NAC}+\mathrm{R}$ \\
\hline 0 & 1 & 1 \\
1 & 2 & 1 \\
2 & 10 & 1 \\
3 & 6 & 0 \\
4 & 7 & 1 \\
6 & 5 & 3 \\
8 & 1 & 4 \\
9 & 1 & 5 \\
12 & 2 & 11 \\
Total & 35 & 27 \\
Weighted score, mean & 3.97 & 8.67 \\
\hline SIRT1, sirtuin1; NAC+OP+R, neoadjuvant chemotherapy + surgery + \\
radiotherapy; NAC+R, neoadjuvant chemotherapy + radiotherapy. \\
\hline
\end{tabular}

in the $\mathrm{NAC}+\mathrm{OP}+\mathrm{R}$ group compared to the $\mathrm{NAC}+\mathrm{R}$ group (4.23 vs. 6.70; $\mathrm{P}<0.001)$.

Correlation between expression of SIRT1 and p53. In total, 19 of the 62 patients showed low expression of SIRT1 and p53, and 18 showed high expression. There was a weak correlation between expression of SIRT1 and p53 (|r|=0.247).

Correlation between expression of SIRT1 and effects of NAC. Of the 35 patients in the NAC+OP+R group, 26 (74\%) showed
Table III. Characteristics of the patients in the low and high SIRT1 expression groups.

\begin{tabular}{lccc}
\hline Characteristics & $\leq 4^{\mathrm{a}}$ & $\geq 6^{\mathrm{a}}$ & P-value \\
\hline Patients, $\mathrm{n}$ & 30 & 32 & \\
Age, years & & & \\
Mean \pm SD & $49.8 \pm 12.4$ & $51.3 \pm 11.8$ & $0.633^{\mathrm{b}}$ \\
Range & $24-69$ & $24-68$ & \\
FIGO stage, $\mathrm{n}$ & & & \\
IIIA & 0 & 1 & $0.329^{\mathrm{c}}$ \\
IIIB & 30 & 31 & \\
Histology, n & & & \\
SCC & 26 & 26 & $0.585^{\mathrm{c}}$ \\
A & 4 & 4 & \\
AS & 0 & 1 & \\
Others & 0 & 1 & \\
\hline
\end{tabular}

${ }^{a}$ Weighted score; ${ }^{b}$ Student's t-test; ${ }^{c} \chi^{2}$ test; NAC+OP+R, neoadjuvant chemotherapy + surgery + radiotherapy; NAC+R, neoadjuvant chemotherapy + radiotherapy; FIGO, International Federation of Gynecology and Obstetrics; SCC, squamous cell carcinoma; A, adenocarcinoma; AS, adenosquamous carcinoma; SD, standard deviation.

Table IV. Weighted scores of $\mathrm{p} 53$ expression in the $\mathrm{NAC}+\mathrm{OP}+\mathrm{R}$ and NAC+R groups.

\begin{tabular}{lcc}
\hline & \multicolumn{2}{c}{ Patients, $\mathrm{n}$} \\
\cline { 2 - 3 } Weighted score & NAC+OP+R & NAC+R \\
\hline 0 & 0 & 1 \\
1 & 2 & 0 \\
2 & 10 & 0 \\
3 & 1 & 3 \\
4 & 12 & 4 \\
6 & 5 & 7 \\
8 & 3 & 6 \\
9 & 1 & 2 \\
12 & 1 & 4 \\
Total & 35 & 27 \\
Weighted score, mean & 4.23 & 6.70 \\
\hline
\end{tabular}

$\mathrm{NAC}+\mathrm{OP}+\mathrm{R}$, neoadjuvant chemotherapy + surgery + radiotherapy; $\mathrm{NAC}+\mathrm{R}$, neoadjuvant chemotherapy + radiotherapy.

Table V. Numbers of patients with low and high SIRT1 expression in the NAC+OP+R and NAC+R groups.

\begin{tabular}{lccc} 
Expression & $\mathrm{NAC}+\mathrm{OP}+\mathrm{R}, \mathrm{n}(\%)$ & $\mathrm{NAC}+\mathrm{R}, \mathrm{n}(\%)$ & $\mathrm{P}$-value \\
\hline Low, $\leq 4$ & $26(87)$ & $4(13)$ & $<0.001^{\mathrm{a}}$ \\
High, $\geq 6$ & $9(28)$ & $23(72)$ &
\end{tabular}

${ }^{\mathrm{a}} \chi^{2}$ test. SIRT1, sirtuin $1 ; \mathrm{NAC}+\mathrm{OP}+\mathrm{R}$, neoadjuvant chemotherapy + surgery + radiotherapy; NAC+R, neoadjuvant chemotherapy + radiotherapy. 

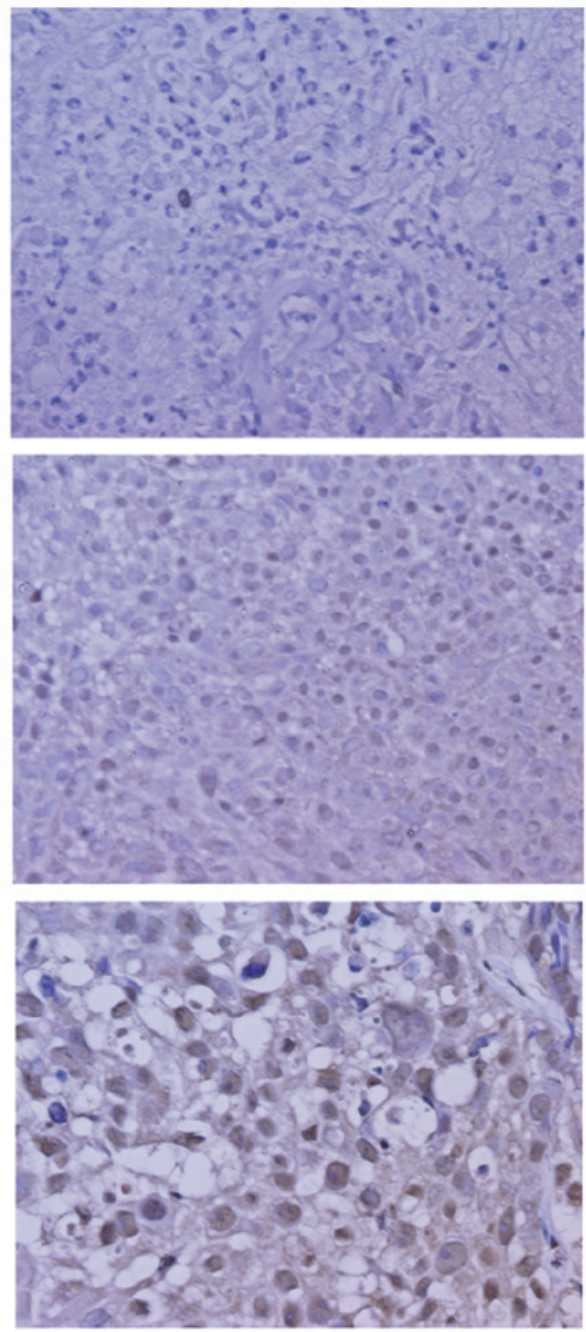

Figure 1. Immunohistochemical staining of SIRT1 in locally advanced cervical cancer. (A) Negative control. (B) Score 1, NAC+OP+R group. (C) Score 2, NAC+OP+R group (A-C, H\&E; magnification, x400). SIRT1 was expressed in the nuclei of the tumor cells. SIRT1, sirtuin 1; NAC+OP+R, neoadjuvant chemotherapy + surgery + radiotherapy; H\&E, hematoxylin and eosin.

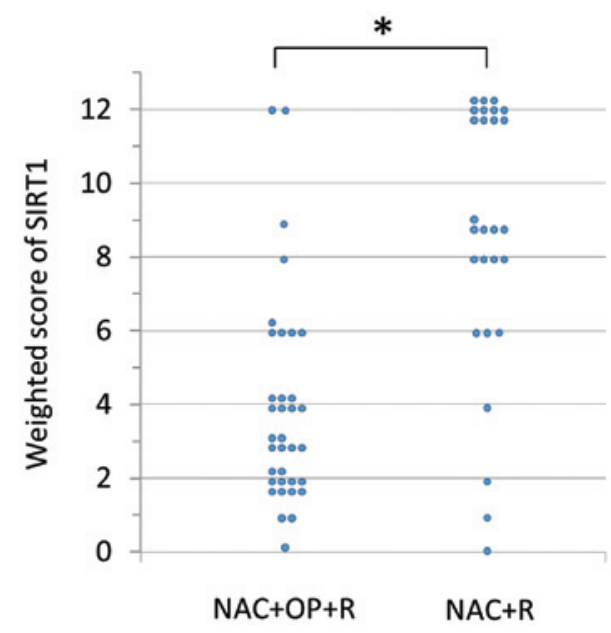

Figure 2. Weighted score for SIRT1 expression in tumor samples from patients with locally advanced cervical cancer. SIRT1 expression was significantly higher in the $\mathrm{NAC}+\mathrm{R}$ compared to the $\mathrm{NAC}+\mathrm{OP}+\mathrm{R}$ group. ${ }^{*} \mathrm{P}<0.001$ (Mann-Whitney U test). SIRT1, sirtuin 1; NAC+R, neoadjuvant chemotherapy + radiotherapy; $\mathrm{NAC}+\mathrm{OP}+\mathrm{R}$, neoadjuvant chemotherapy + surgery + radiotherapy.

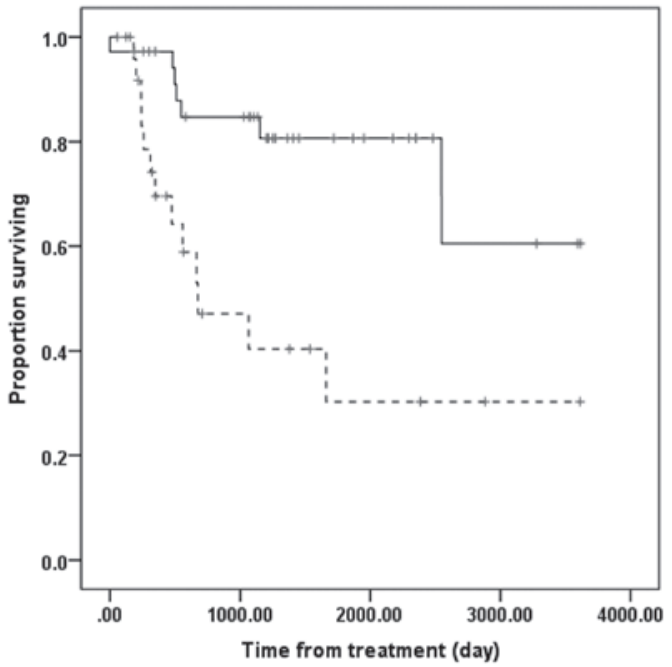

Figure 3. Overall survival rate in the $\mathrm{NAC}+\mathrm{OP}+\mathrm{R}(\mathrm{n}=35)$ and $\mathrm{NAC}+\mathrm{R}(\mathrm{n}=27)$ groups. Solid line, $\mathrm{NAC}+\mathrm{OP}+\mathrm{R}$; dashed line, $\mathrm{NAC}+\mathrm{R}$. $\mathrm{NAC}+\mathrm{OP}+\mathrm{R}$ group showed significantly improved overall survival time compared to $\mathrm{NAC}+\mathrm{R}$ group ( $\mathrm{P}=0.001$, Kaplan-Meier and log-rank tests). NAC+OP+R, neoadjuvant chemotherapy + surgery + radiotherapy; NAC+R, neoadjuvant chemotherapy + radiotherapy.

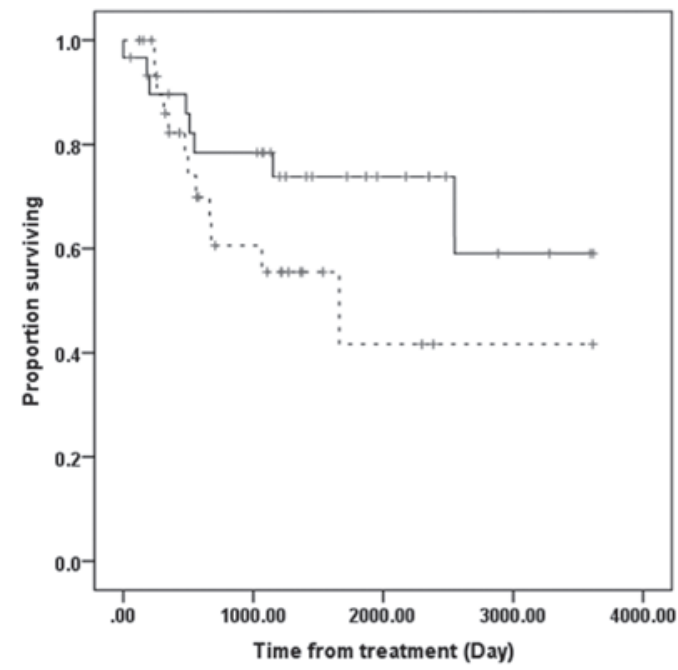

Figure 4. Overall survival rate in the low $(\mathrm{n}=30)$ and high SIRT1 expression $(\mathrm{n}=32)$ groups. Solid line, low SIRT1 expression; dashed line, high SIRT1 expression. There was no significant difference in overall survival between the two groups ( $\mathrm{P}=0.143$, Kaplan-Meier and log-rank tests). SIRT1, sirtuin1.

low SIRT1 expression, whereas nine (26\%) showed high SIRT1 expression. The group with low SIRT1 expression was significantly more sensitive to NAC $(\mathrm{P}=0.001$; Table V).

Survival. The overall survival time was significantly longer in the NAC+OP+R compared to the NAC+R group (Fig. 3). However, overall survival was similar in patients with low and high SIRT1 expression (Fig. 4).

\section{Discussion}

The results of the present study show the association between the expression of SIRT1 and the efficacy of NAC. NAC was 
ineffective in the majority of patients with high SIRT1 expression, who were unable to undergo surgery. Overall survival time was significantly longer in the $\mathrm{NAC}+\mathrm{OP}+\mathrm{R}$ compared to the $\mathrm{NAC}+\mathrm{R}$ group. These results are in agreement with findings showing that prognosis is worse when NAC is unsuccessful $(21,22)$. By contrast, overall survival time did not differ significantly in the groups of patients with high and low SIRT1 expression.

In general, CCRT is considered the standard treatment for patients with locally advanced, uterine cervical cancer. However, limited clinical studies have assessed CCRT in Japanese patients with locally advanced, uterine cervical cancer. Although surgery following NAC has been reported effective (20), NAC is not currently recommended, as if NAC is not effective, surgery is difficult to perform and radiation therapy is required. Radiation therapy following chemotherapy has shown poorer prognosis compared to radiation alone $(21,22)$. Thus, identifying factors prognostic of the efficacy of NAC is important in patients with locally advanced uterine cervical cancer.

SIRT1 is a member of the silent information regulator 2 (Sir2) family in mammals, with activity as an $\mathrm{NAD}^{+}$-dependent HDAC (1-3). SIRT1 deacetylates several key cell-cycle and apoptosis regulating proteins (4-7). SIRT1 expression has been reported to increase in various human malignant tumors. SIRT1 is considered a tumor promoter, as it inhibits tumor suppressor genes such as p53 (14,15). SIRT1 overexpression has been associated with primary tumorigenesis, metastasis, chemoresistance and patient prognosis. However, other studies have reported that SIRT1 may act as a tumor suppressor $(32,33)$.

The present study is the first to report a correlation between SIRT1 expression and locally advanced, uterine cervical cancer. These findings indicate that NAC may be more effective in patients with low compared to high SIRT1 expression, suggesting that SIRT1 expression may predict the efficacy of NAC in patients with locally advanced, uterine cervical cancer. As overexpression of SIRT1 has been associated with chemoresistance, lower SIRT1 expression may result in tumor susceptibility to treatment. When the correlation between p53 expression and NAC was assessed in patients with locally advanced, uterine cervical cancer, the observed results were similar to those for SIRT1 and NAC ( $\mathrm{P}=0.001$; data not shown). A weak correlation was also observed between SIRT1 and p53 expression. Human papillomavirus (HPV) infection causes the majority of uterine cervical cancers, with the viral E6 and E7 proteins playing important roles in tumor progression (34). The E6 protein targets p53, inducing a loss of p53 tumor suppressor activity, such as apoptosis $(35,36)$. By contrast, HPV E7 protein has been reported to activate SIRT1 expression, leading to a defective apoptotic response (37). Thus, HPV infection enhances SIRT1 and p53 expression, providing further evidence for the significant role of SIRT1 in cervical cancer.

If NAC is not successful in patients with locally advanced, uterine cervical cancer, their prognosis becomes worse. Therefore, it is important to identify factors prognostic of the success of NAC in these patients. SIRT1 expression may predict the efficacy of NAC as a treatment for locally advanced, uterine cervical cancer. Our previous study reported that the expression of bax, bcl-xL, and MAD2 (mitotic arrest deficiency 2) proteins may predict the efficacy of NAC in patients with locally advanced, uterine cervical cancer $(25,38)$. Taken together, a combination of these factors may more effectively predict the efficacy of NAC in these patients.

\section{References}

1. Blander G and Guarente L: The Sir2 family of protein deacetylases. Annu Rev Biochem 73: 417-435, 2004.

2. Imai S, Armstrong CM, Kaeberlein $M$ and Guarente L: Transcriptional silencing and longevity protein Sir2 is an NAD-dependent histone deacetylase. Nature 403: 795-800, 2000.

3. Voelter-Mahlknecht S and Mahlknecht U: Cloning, chromosomal characterization and mapping of the NAD-dependent histone deacetylases gene sirtuin 1. Int J Mol Med 17: 59-67, 2006.

4. Brunet A, Sweeney LB, Sturgill JF, Chua KF, Greer PL, Lin Y, Tran H, Ross SE, Mostoslavsky R, Cohen HY, Hu LS, Cheng HL, Jedrychowski MP, Gygi SP, Sinclair DA, Alt FW and Greenberg ME: Stress-dependent regulation of FOXO transcription factors by the SIRT1 deacetylase. Science 303: 2011-2015, 2004.

5. Cohen HY, Lavu S, Bitterman KJ, Hekking B, Imahiyerobo TA, Miller C, Frye R, Ploegh H, Kessler BM and Sinclair DA: Acetylation of the $\mathrm{C}$ terminus of $\mathrm{Ku} 70$ by $\mathrm{CBP}$ and PCAF controls Bax-mediated apoptosis. Mol Cell 13: 627-638, 2004.

6. Luo J, Nikolaev AY, Imai S, Chen D, Su F, Shiloh A, Guarente L and $\mathrm{Gu}$ W: Negative control of p53 by Sir2alpha promotes cell survival under stress. Cell 107: 137-148, 2001.

7. Vaziri H, Dessain SK, Ng Eaton E, Imai SI, Frye RA, Pandita TK, Guarente L and Weinberg RA: hSIR2(SIRT1) functions as an NAD-dependent p53 deacetylase. Cell 107: 149-159, 2001.

8. Hida Y, Kubo Y, Murao K and Arase S: Strong expression of a longevity-related protein, SIRT1, in Bowen's disease. Arch Dermatol Res 299: 103-106, 2007.

9. Huffman DM, Grizzle WE, Bamman MM, Kim JS, Eltoum IA, Elgavish A and Nagy TR: SIRT1 is significantly elevated in mouse and human prostate cancer. Cancer Res 67: 6612-6618, 2007.

10. Kuzmichev A, Margueron R, Vaquero A, Preissner TS, Scher M, Kirmizis A, Ouyang X, Brockdorff N, Abate-Shen C, Farnham P and Reinberg D: Composition and histone substrates of polycomb repressive group complexes change during cellular differentiation. Proc Natl Acad Sci USA 102: 1859-1864, 2005.

11. Jang KY, Kim KS, Hwang SH, Kwon KS, Kim KR, Park HS, Park BH, Chung MJ, Kang MJ, Lee DG and Moon WS: Expression and prognostic significance prognostic of SIRT1 in ovarian epithelial tumours. Pathology 41: 366-371, 2009.

12. Chen HC, Jeng YM, Yuan RH, Hsu HC and Chen YL: SIRT1 promotes tumorigenesis and resistance to chemotherapy in hepatocellular carcinoma and its expression predicts poor prognosis. Ann Surg Oncol 19: 2011-2019, 2012.

13. Chen WY, Wang DH, Yen RC, Luo J, Gu W and Baylin SB: Tumor suppressor HIC1 directly regulates SIRT1 to modulate p53-dependent DNA-damage responses. Cell 123: 437-448, 2005.

14. Baylin SB and Ohm JE: Epigenetic gene silencing in cancer - a mechanism for early oncogenic pathway addiction? Nat Rev Cancer 6: 107-116, 2006.

15. Lim CS: Human SIRT1: a potential biomarker for tumorigenesis? Cell Biol Int 31: 636-637, 2007.

16. Japan Society of Gynecologic Oncology (eds): Formulation Committee of the Treatment Guidelines for Cervical Cancer. Kanehara \& Co., Tokyo, 2011 (In Japanese).

17. National Comprehensive Cancer Network: NCCN Clinical Practice Guidelines in Oncology - Cervical Cancer - Version II, 2013.

18. Morris M, Eifel PJ, Lu J, Grigsby PW, Levenback C, Stevens RE, Rotman M, Gershenson DM and Mutch DG: Pelvic radiation with concurrent chemotherapy compared with pelvic and para-aortic radiation for high-risk cervical cancer. N Engl J Med 340: 1137-1143, 1999.

19. Eifel PJ, Winter K, Morris M, Levenback C, Grigsby PW, Cooper J, Rotman M, Gershenson D and Mutch DG: Pelvic irradiation with concurrent chemotherapy versus pelvic and para-aortic irradiation for high-risk cervical cancer: an update of radiation therapy oncology group trial (RTOG) 90-01. J Clin Oncol 22: 872-880, 2004.

20. Ishiko O, Sumi T, Yasui T, Matsumoto Y, Kawamura N, Ogita S, Kamino T, Nakamura K and Yamada R: Balloon-occluded arterial infusion chemotherapy, simple total hysterectomy, and radiotherapy as a useful combination-therapy for advanced cancer of the uterine cervix. Oncol Rep 7: 141-144, 2000. 
21. Souhami L, Gil RA, Allan SE, Canary PC, Araújo CM, Pinto LH and Silveira TR: A randomized trial of chemotherapy followed by pelvic radiation therapy in stage IIIB carcinoma of the cervix. J Clin Oncol 9: 970-977, 1991.

22. Tattersall MH, Lorvidhaya V, Vootiprux V, Cheirsilpa A, Wong F, Azhar T, Lee HP, Kang SB, Manalo A and Yen MS: Randomized trial of epirubicin and cisplatin chemotherapy followed by pelvic radiation in locally advanced cervical cancer. Cervical Cancer Study Group of the Asian Oceanian Clinical Oncology Association. J Clin Oncol 13: 444-451, 1995.

23. Ishiko O, Sumi T, Yasui T, Matsumoto Y, Ogita S, Kaminou T, Nakamura $\mathrm{K}$ and Yamada R: Tumor marker and MR imaging criteria for evaluating the efficacy of cyclic balloon-occluded arterial infusion for advanced cancer of the uterine cervix. Oncol Rep 7: 827-830, 2000.

24. Ishiko O, Sumi T, Yoshida H, Ogita S and Yamada R: Expression of apoptosis regulatory proteins in advanced cancer of the uterine cervix after cyclic balloon-occluded arterial infusion chemotherapy. Int J Oncol 18: 1151-1155, 2001.

25. Okamoto E, Sumi T, Misugi F, Nobeyama H, Hattori K, Yoshida H Matsumoto Y, Yasui T, Honda K and Ishiko O: Expression of apoptosis-related proteins in advanced uterine cervical cancer after balloon-occluded arterial infusion chemotherapy as an indicator of the efficiency of this therapy. Int J Mol Med 15: 41-47, 2005.

26. Nobeyama H, Sumi T, Misugi F, Okamoto E, Hattori K, Matsumoto Y, Yasui T, Honda K, Iwai K and Ishiko O: Association of HPV infection with prognosis after neoadjuvant chemotherapy in advanced uterine cervical cancer. Int $\mathbf{J}$ Mol Med 14: 101-105, 2004.

27. Benedetti Panici P, Bellati F, Manci N, Pernice M, Plotti F, Di Donato V, Calcagno M, Zullo MA, Muzii L and Angioli R: Neoadjuvant chemotherapy followed by radical surgery in patients affected by FIGO stage IVA cervical cancer. Ann Surg Oncol 14: 2643-2648, 2007.

28. Tsuji K, Yamada R, Kawabata M, Mitsuzane K, Sato M, Iwahashi M, Kitayama S and Nakano R: Effect of balloon occluded arterial infusion of anticancer drugs on the prognosis of cervical cancer treated with radiation therapy. Int J Radiat Oncol Biol Phys 32: 1337-1345, 1995.
29. Sironi S, Belloni C, Taccagni G and DelMaschio A: Invasive cervical carcinoma: MR imaging after preoperative chemotherapy. Radiology 180: 719-722, 1991.

30. Kim KH, Lee BH, Do YS, Chin SY, Park SY, Kim BG and Jang JJ: Stage IIb cervical carcinoma: MR evaluation of effect of intraarterial chemotherapy. Radiology 192: 61-65, 1994.

31. Sinicrope FA, Ruan SB, Cleary KR, Stephens LC, Lee JJ and Levin B: bcl-2 and p53 oncoprotein expression during colorectal tumorigenesis. Cancer Res 55: 237-241, 1995.

32. Firestein R, Blander G, Michan S, Oberdoerffer P, Ogino S, Campbell J, Bhimavarapu A, Luikenhuis S, de Cabo R, Fuchs C, Hahn WC, Guarente LP and Sinclair DA: The SIRT1 deacetylase suppresses intestinal tumorigenesis and colon cancer growth. PLoS One 3: e2020, 2008.

33. Wang RH, Zheng Y, Kim HS, Xu X, Cao L, Luhasen T, Lee MH, Xiao C, Vassilopoulos A, Chen W, Gardner K, Man YG, Hung MC, Finkel T and Deng CX: Interplay among BRCA1, SIRT1, and Survivin during BRCA1-associated tumorigenesis. Mol Cell 32: 11-20, 2008

34. zur Hausen H: Papillomaviruses causing cancer: evasion from host-cell control in early events in carcinogenesis. J Natl Cancer Inst 92: 690-698, 2000.

35. Werness BA, Levine AJ and Howley PM: Association of human papillomavirus types 16 and 18 E6 proteins with p53. Science 248: 76-79, 1990.

36. Bremer GL, Tieboschb AT, van der Putten HW, de Haan J and Arends JW: p53 tumor suppressor gene protein expression in cervical cancer: relationship to prognosis. Eur J Obstet Gynecol Reprod Biol 63: 55-59, 1995.

37. Allison SJ, Jiang M and Milner J: Oncogenic viral protein HPV E7 up-regulates the SIRT1 longevity protein in human cervical cancer cells. Aging (Albany NY) 1: 316-327, 2009.

38. Morishita M, Sumi T, Nakano Y, Teramae M, Fukuda T, Nobeyama H, Yoshida H, Matsumoto Y, Yasui T and Ishiko O: Expression of mitotic-arrest deficiency 2 predicts the efficacy of neoadjuvant chemotherapy for locally advanced uterine cervical cancer. Exp Ther Med 3: 341-346, 2011. 